\title{
Analysis of MOSFET Failure Modes in Bi-directional Phase-Shift Full-Bridge Converters
}

\author{
Chang-Yeol Oh*, Won-Yong Sung*, Yun-Sung Kim** and Byoung-Kuk Lee ${ }^{\dagger}$
}

\begin{abstract}
This paper presents an analysis of the mechanism of failure modes in bi-directional phaseshift full-bridge converters, composed of MOSFET, based on the circuit operation and parasitic parameters of MOSFET. In addition, the relation between circuit operation and parameters is suggested through an experimental comparison. From this relation, the suitable ranges of parameters for stable performance are analyzed. The design criteria of the bi-directional phase-shift full-bridge converter are presented and evaluated from the experimental verification.
\end{abstract}

Keywords: Bi-directional Full-bridge converters, Bi-directional Phase-shift, Failure modes, MOSFET fault, MOSFET failure modes

\section{Introduction}

As the development of vehicle to grid systems and renewable energy sources or battery energy storage systems has been actively progressing, the bi-directional converter has continued to receive attention as the effective power transfer unit from the battery to the energy source [1-4].

Among the various types of bi-directional converter topologies, the bi-directional phase-shift full-bridge (PSFB) topology with dual active bridge (DAB) as shown in Fig. 1 is regarded as a preferred option with its advantages such as isolation among energy sources, medium / high power capacity with high efficiency, stability, and reliability [1, 7-12].

The elements affecting performance and stability of the bi-directional PSFB converter can be listed as controller configuration, design of magnetic components, and selection of switching devices. Among these, MOSFETs substantially influence the characteristics of the overall performance. Especially, in the case of bi-directional operation, the primary and secondary sides of PSFB converters consist of MOSFETs, so that the effect of parasitic components becomes more serious [7]-[12].

The important considerations in selecting the MOSFET applied to the bi-directional PSFB converters are parasitic output capacitance $\left(\mathrm{C}_{\text {oss }}\right)$ for resonant condition, conductive resistance $\left(\mathrm{R}_{\mathrm{ds}, \mathrm{on}}\right)$ to reduce conduction losses, and gate drive charge $\left(\mathrm{Q}_{\mathrm{g}}\right)$ for stable gate drive. Also, in particular reverse-recovery characteristics of body diode $\left(t_{\mathrm{rr}}\right.$ or $\left.\mathrm{Q}_{\mathrm{rr}}\right)$ and gate charging capacitance $\left(\mathrm{C}_{\mathrm{gd}}\right)$ are additionally considered. As the body diodes are used to rectify the

$\dagger$ Corresponding Author: College of Information and Communication Engineering, Sungkyunkawn University, Korea. (bkleeskku@skku.edu)

* College of Information and Communication Engineering, Sungkyunkawn University, Korea. (danie106@skku.edu)

** Research \& Development Center at Dongahelecomm Corporation, Korea. (yunsk@dongahelecomm.co.kr)

Received: October 9, 2014; Accepted: April 30, 2015

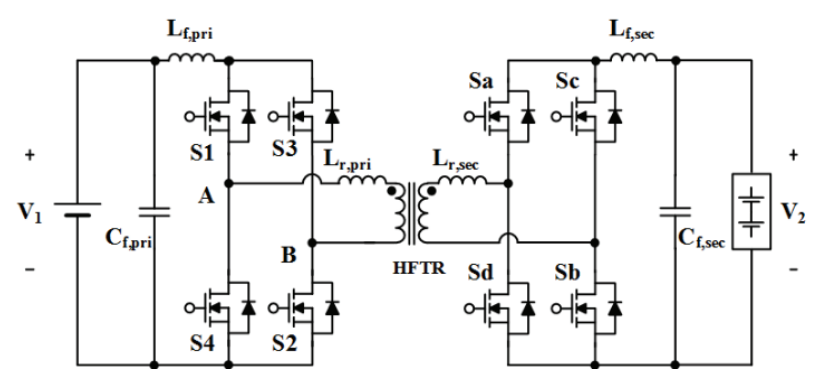

Fig. 1. Configurations of bi-directional PSFB converter using MOSFETs

secondary side of the PSFB converter in the DAB structure, the reverse-recovery current $\left(\mathrm{I}_{\mathrm{rr}}\right)$, which is determined by the reverse-recovery characteristics of the DAB structure, is reflected on the primary side and added to the voltage stress of the switching devices [12-15].

Moreover, the failure of devices in the secondary side also occurs in the operation of the rectifier. In addition, the gate charging capacitance $\left(\mathrm{C}_{\mathrm{gd}}\right)$ is important to ensure the stable gate driving of MOSFET from the instantaneous voltage/current stress caused by the increased parasitic parameters and $\mathrm{I}_{\mathrm{rr}}$. Considering the above-mentioned phenomena, the appropriate design process of the bidirectional PSFB converter should be performed. However, the failure modes occasionally appear in this converter because of the insufficient consideration of the design criteria of the parameters [1, 6-9, 14].

Therefore, in this paper, the analysis of the mechanism of the failure modes in the bi-directional PSFB converter using MOSFET is presented on the basis of the operation of the circuit and parasitic components of MOSFET. Based on the result of the analysis, each parameter that affects the failure modes is described. By considering these parameters, desirable MOSFETs for achieving high efficiency in the PSFB converter are determined, and appropriate MOSFETs are reclassified for the stable 
operation of the bi-directional type.

In this procedure, an experimental comparison is carried out to evaluate the parameters of the selected MOSFETs on the circuit operation, considering transient characteristics of the bi-directional PSFB converter.

\section{Analysis of Failure Modes Mechanism}

Failure modes in the bi-directional PSFB converter mainly occur in two conditions of circuit configuration, such as the transient in the circuit operation and the false operation of the MOSFETs in the full-bridge configuration by the reverse recovery current of the body diode [1].

\subsection{Failure mode in circuit operation}

The circuit operation of the PSFB converter can be divided into the leading-leg transition and the laggingleg transition. In the conversion of both operations, the transient voltage spike, after freewheeling in the primary side and commutating in the secondary side by the circuit operation, induces the failure modes of the MOSFETs and the body diodes as shown in Fig. 2 [1].

In the leading leg transition, the filter inductor current simultaneously charges and discharges the output capacitance

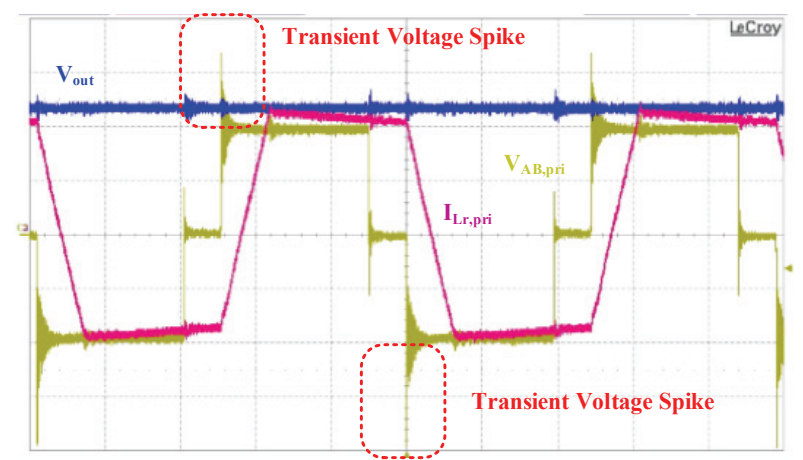

Ch1: $V_{A B, p r i}\left(200 \mathrm{~V} /\right.$ div) / Ch2: $I_{\text {Lr,pri }}\left(2 \mathrm{~A} /\right.$ div) / Ch3: V out $_{\text {out }}$ (100V/div) [Time: 2us/div]

(a) Transient voltage spike in primary side

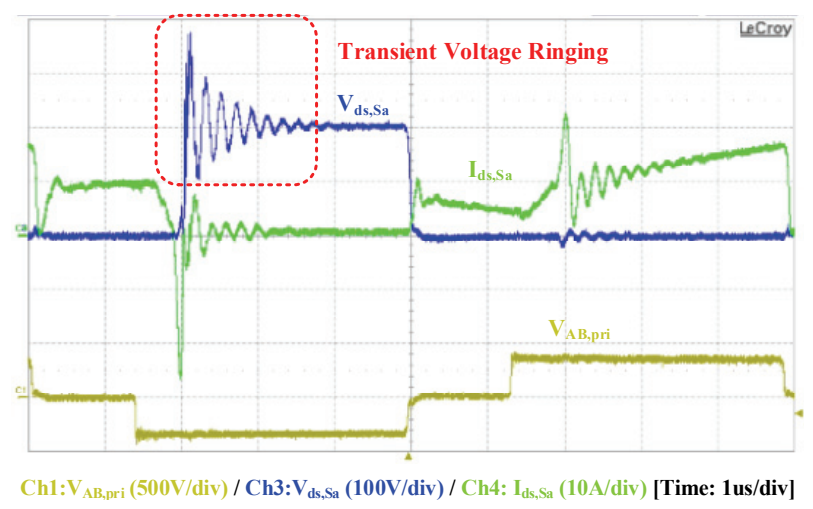

(b) Transient voltage spike in secondary side

Fig. 2. Transient voltage spike due to the circuit operation

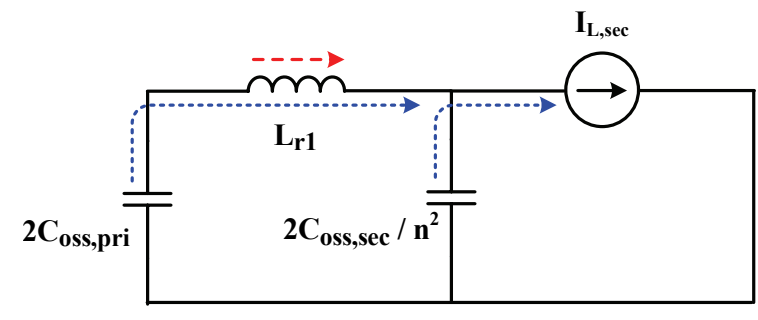

(a) Leading leg

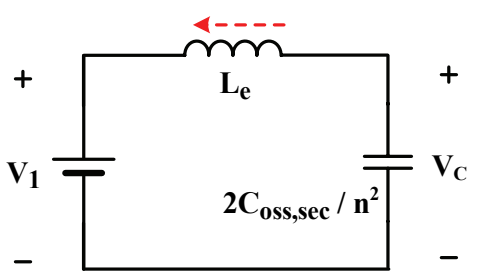

(b) Leading leg

Fig. 3. Equivalent circuit in the operation of bi-directional PSFB

of the switches in the primary and secondary sides of PSFB. In this process, the converter consists of an LC resonant network and it generates current resonance. In the resonant condition, the voltage across the primary switches and the rectified voltage in the secondary side are linearly decreased. The currents through both inductors can be treated as current sources, because the filter inductor and the magnetizing inductor of the transformer are relatively larger than the resonant inductor. The current flowed from the current sources linearly discharges the energy stored in the capacitors without the transient voltage.

In the lagging leg transition, on the other hand, the LC resonant circuit with the input voltage source induces the voltage spike.

Both transient operations of the bi-directional PSFB converter can be represented by the equivalent circuits as shown in Fig. 3. Fig. 3(a) indicates the equivalent circuit of the leading leg transition. In this condition, $2 \mathrm{C}_{\mathrm{oss} \text { pri }}$ and $2 \mathrm{C}_{\text {oss,sec }}$, which are respectively parasitic capacitors of two MOSFETs in primary bridge and secondary bridge rectifier, construct a parallel configuration. The current through the primary resonant inductor $\mathrm{I}_{\mathrm{Lr} \text {,pri }}$ and the current $\mathrm{I}_{\mathrm{L}, \mathrm{sec}}$, which current of the filter inductor with a secondary resonant inductor, charge and discharge the capacitor simultaneously.

Since $\mathrm{I}_{\mathrm{L}, \mathrm{sec}}$ can be treated as the current source, the energy stored in the capacitors is discharged without the transient state. At that time, the equivalent parameters can be represented as follows:

$$
I_{L, \mathrm{sec}}=I_{L r, \mathrm{sec}}+\left(I_{L f, \mathrm{sec}} / n\right)+I_{L m}
$$

On the other hand, as shown in Fig. 3(b), the equivalent inductor $\mathrm{L}_{\mathrm{e}}$, which is the sum of the primary resonant inductor $\mathrm{L}_{\mathrm{r} \text {,pri }}$ and the reflected secondary resonant inductor $\mathrm{L}_{\mathrm{r}, \mathrm{sec}}$, and $2_{\text {Coss,sec }}$ consist of an LC resonant network in the lagging led transition. In this equivalent circuit, the 
equivalent inductor $\mathrm{L}_{\mathrm{e}}$ is defined as follows:

$$
L_{e}=L_{r, p r i}+\left(L_{r, s e c} / n^{2}\right)
$$

The equivalent LC resonant network generates the voltage resonance with the input voltage source. Thus, the voltage oscillation is induced and it can be represented as follows:

$$
V_{C}(t)=V_{S}-V_{S} \cos \left\{\omega_{0}\left(t-t^{\prime}\right)\right\}
$$

As the voltage resonance effects to the rectifying voltage of the secondary side, the voltage stress affects on MOSFETs in the secondary bridge as well as in the primary bridge. The voltage stress on the secondary bridge can be expressed as follows:

$$
\begin{aligned}
V_{r e c, \mathrm{sec}}(t) & =\frac{N_{2}}{N_{1}} \cdot V_{C, p r i}(t) \\
& =\frac{N_{2}}{N_{1}} \cdot\left[V_{S}-V_{S} \cos \left\{\omega_{0}\left(t-t^{\prime}\right)\right\}\right]
\end{aligned}
$$

where $\omega_{0}$ is the resonant frequency of the LC network in the lagging leg transition as defined in (5)

$$
\omega_{0}=\frac{1}{\sqrt{\left(L_{r 1}+L_{r 2} / n^{2}\right)\left(2 C_{o s s, s e c} / n^{2}\right)}}
$$

In this transient analysis, not only $\mathrm{C}_{\mathrm{oss}}$ but also the ratio between resonant inductance and magnetizing inductance influence on magnitudes of the transient voltage across MOSFETs in the primary and secondary bridge. Also, the reverse recovery current of body diodes in rectifying bridge side also generates a voltage overshoot with the stray inductance of the circuit. Therefore, the design of bidirectional PSFB should be performed using MOSFET with fast-recovery body diode and the stray inductance of the circuit should be minimized.

\subsection{Failure mode in false operation of devices}

The main reason for the device false operation in the full-bridge configuration is the reverse recovery current of the body diode. The reverse recovery of body diodes raises serious issues not only in terms of the voltage oscillation in the primary bridge with the overvoltage failure of the MOSFETs, but also the performance of the bi-directional power conversion and transfer from the input source to the output load. Careful consideration in the design of MOSFETs in the bi-directional PSFB converter is therefore required because the false operation of devices according to the reverse recovery current from the body diode can generate a failure mode as shown in Fig. 4. When the false operation of devices is happened, arm short is instantaneously occurred in a single leg of the full-bridge and short through current flows through the leg, as shown in Fig. 4. As the energy is not transferred to output under the influence of arm short, the output voltage becomes nearly zero. The remained energy cause the current level to be increased in primary side and the growing current stress of MOSFETs in primary full-bridge leads to failure.

Due to the false operation of the MOSFET, the failure mode in the bridge structure has been studied in previous work. However, most studies have focused on the numerical analysis and the empirical results with the statistical method because the factor of the failure mode is formed from the structure and the manufacturing process of the semiconductor device [13-15]. Moreover, the requirement for high efficiency devices has motivated the development of various semiconductor structures of the

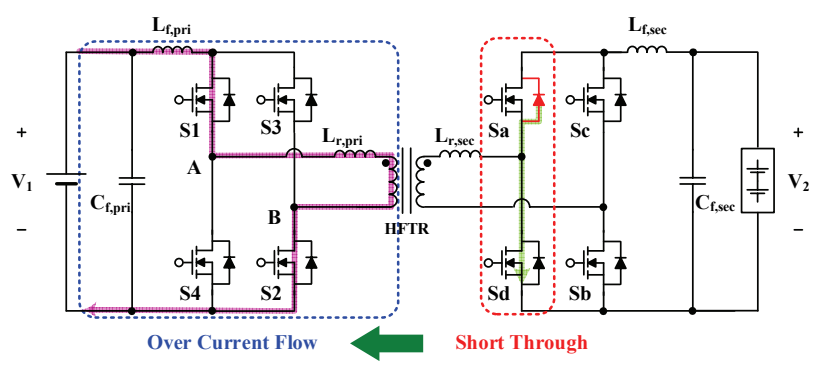

(a) Failure effects on the circuit

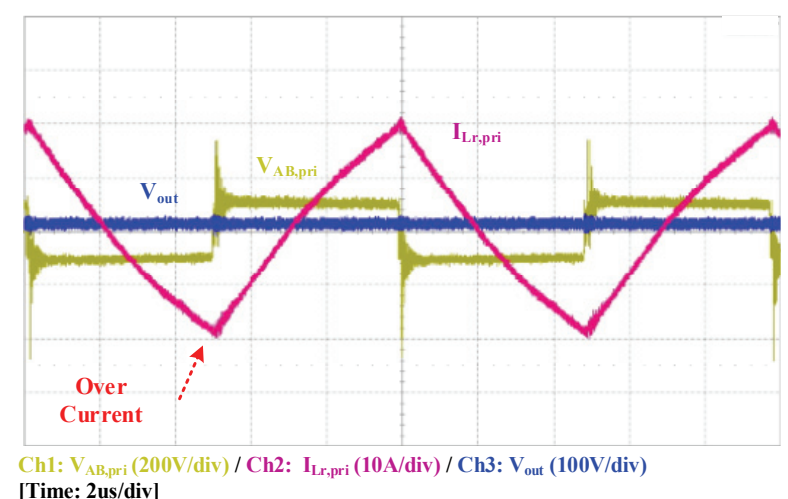

[Time: 2us/div]

(b) Failure waveforms of primary side

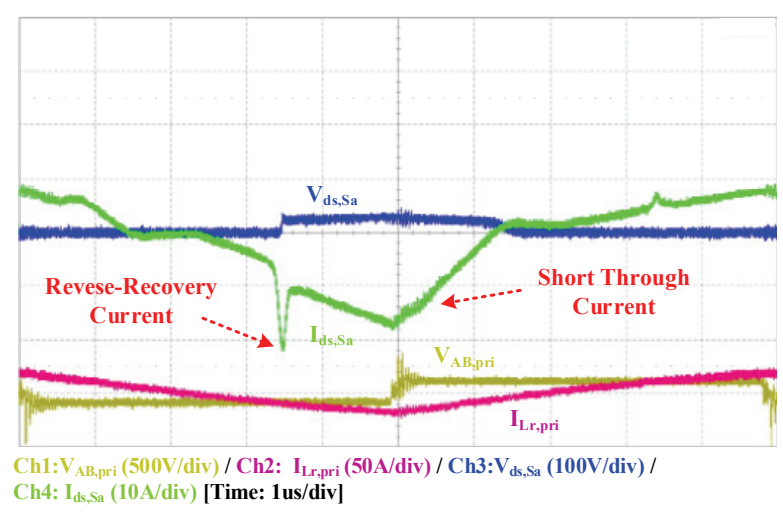

(c) Failure waveforms of secondary side

Fig. 4. Failure mode operation due to reverse-recovery of body diode 


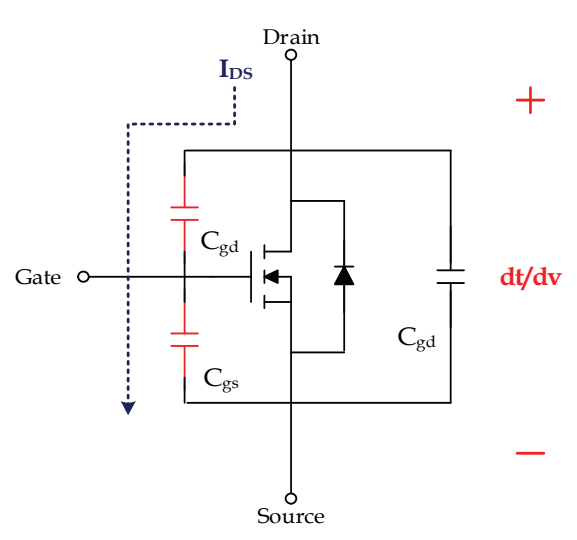

Fig. 5. Mechanism of dynamic turn-on

device, depending on the manufacturer. For this reason, numerical analysis using the quantified parameters becomes more complex. Thus, the additional design parameters are necessary to avoid the false operation of the MOSFET caused by the reverse recovery characteristic of body diode.

Two main reasons for the false operation of the MOSFET are the $\mathrm{dv} / \mathrm{dt}$ caused by the stray inductance and the parasitic BJT. The false operation of the MOSFET due to the $\mathrm{dv} / \mathrm{dt}$ is called dynamic turn-on. When the reverse recovery current of the body diode occurs, the rapid current transition generates a large $\mathrm{dv} / \mathrm{dt}$ with the stray inductance. The $\mathrm{dv} / \mathrm{dt}$ is applied across the drain-source of the MOSFET. The applied dv/dt induces the current through the gate capacitance of the MOSFET and the current induces dynamic turn-on as shown in Fig. 5. The generation condition of the dynamic turn-on can be represented by the terms of the minimum turn-on threshold voltage $\mathrm{V}_{\mathrm{gs}(\mathrm{th})}$, the maximum transient voltage across drainsource $\mathrm{V}_{\mathrm{ds} \text {,max }}$, and the critical charge through gate-drain $\mathrm{Q}_{\mathrm{gd}, \text { crit }}$ as follows:

$$
\begin{aligned}
& \frac{Q_{g d, c r i t}}{V_{G S(t h)} C_{g s}}<1 \\
& \int_{0}^{V_{d s, \text { max }}-V_{t h, \text { min }}} C_{g d} d V_{g d}=Q_{g d, c r i t}
\end{aligned}
$$

From (6) and (7), the decrease of the charge applied on the gate-drain can prevent dynamic turn-on. As shown in (7), the $\mathrm{C}_{\mathrm{gd}}$ is integrated by the variance of the gate-drain voltage from 0 to the difference between the $\mathrm{V}_{\mathrm{ds} \text {,max }}$ and $\mathrm{V}_{\mathrm{gs}(\mathrm{th})}$ to determine the $\mathrm{Q}_{\mathrm{gd} \text {,crit. }}$. Therefore, the small $\mathrm{C}_{\mathrm{gd}}$ and the high $\mathrm{V}_{\mathrm{gs}(\mathrm{th})}$ are needed to avoid the dynamic turn-on represented as the critical charge through gate-drain. Additionally, the small $\mathrm{C}_{\mathrm{gd}}$ reduces the influence of the

Miller effect, so that it can reduce switching time and switching losses when the MOSFET turns on and off. At this time, the increase range of $\mathrm{V}_{\mathrm{gs}(\mathrm{th})}$ is needed to bigger than the decrease range of $\mathrm{C}_{\mathrm{gd}}$, as represented in (6). However, the increase of the $\mathrm{V}_{\mathrm{gs}(\mathrm{th})}$ links to the increase of the driving power to maintain the channel in on-state. Thus, the ratio between $\mathrm{V}_{\mathrm{gs}(\mathrm{th})}$ and $\mathrm{C}_{\mathrm{gd}}$ should be considered to
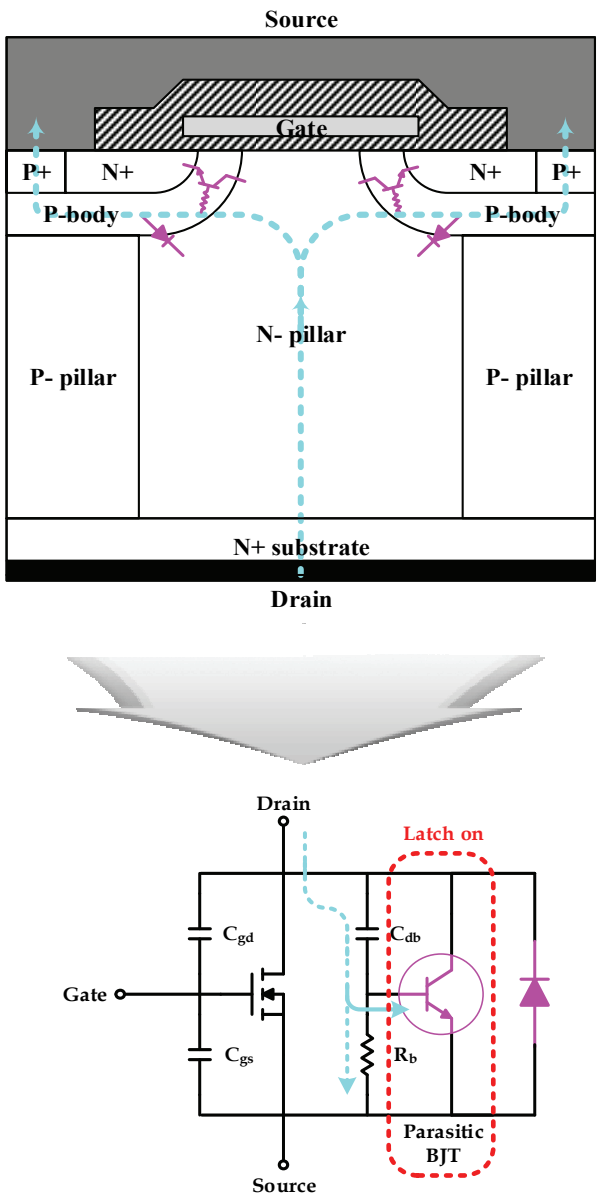

Fig. 6. Equivalent models of MOSFET and mechanism of its dynamic turn-on

avoid the dynamic turn-on with efficient gate driving in MOSFET

The other false operation of the MOSFET derives from the turn-on state of the parasitic BJT. In addition, the MOSFET contains a parasitic BJT with a body diode because of its internal semiconductor structure as shown in Fig. $6[1,14,15]$.

Theoretically, the base and emitter of parasitic BJT are shorted together by the source metal. In practice, however, the small parasitic resistances, determined by the length of the P-body layer, exist in the layer of the semiconductor structure and the resistance works as a base resistor.

When the reverse recovery current is applied to the drain, the current is normally blocked by the body diode. At this time, the displacement current through the coupling capacitor $\mathrm{C}_{\mathrm{db}}$ to the base of the BJT is large enough to induce a voltage drop in the parasitic resistance of the Pbody layer connecting the base and the emitter.

The voltage across the resistance is then worked as the base-emitter voltage $\mathrm{V}_{\mathrm{BE}}$ of the parasitic BJT and it turns on, temporarily. The large current instantaneously flows from the drain through the P-body layer to the source due to this unwanted turn-on. The current leads to a latch-up so that the BJT maintains the turn-on state, by $\mathrm{C}_{\mathrm{db}}$ and $\mathrm{R}_{\mathrm{b}}$. 
Two false operation mechanisms of the MOSFET trigger the arm short-circuit in one leg of the bridge rectifier structure. According to these phenomena, the MOSFETs break down due to the short through current. The factor in common between mechanisms of both false operations results from the reverse recovery characteristic of the body diode in MOSFET. Therefore, unlike the conventional PSFB converter, the reverse recovery charge $Q_{\text {rr }}$ and reverse recovery time $t_{\mathrm{rr}}$, which can be recognized as the reverse recovery characteristic of the body diode, should be considered in the design of the bi-directional PSFB converter.

\section{Experimental Comparison for Design MOSFETs of Bi-Directional PSFB}

For the design of MOSFETs in the bi-directional PSFB converter, the suitability of the design is evaluated through a parameter analysis and experimental comparison with various devices. The parameters of the MOSFET can be derived from the datasheet given by the manufacturer.

However, as mentioned above, the property of the parasitic BJT and the resistance of the P-body layer are altered according to the manufacturing process and the internal structure.

Hence, the exact measurement of values and the numerical analysis with the equivalent modeling are obscure. Therefore, the effects of the parasitic components are discussed with regard to various MOSFETs through the result of the parameter analysis and the experimental comparison.

Based on the derived design parameters from the analysis of the failure modes mechanism, the suitability of each MOSFET is primarily determined.

The analysis and the comparison of the parameters are performed using the various MOSFETs as shown in Table 1. Before the empirical comparison, the suitability of the MOSFETs in the table is determined, through the criteria which are mentioned design parameters $\left(\mathrm{V}_{\mathrm{GS}(\mathrm{th})}\right.$, $\mathrm{C}_{\mathrm{gd}}, \mathrm{Q}_{\mathrm{rr}}$, etc.) with the conventional parameters. MOSFET $\mathrm{C}$, MOSFET E, and MOSFET $\mathrm{F}$ are sorted according to the analysis and comparison of the parameters. MOSFET $\mathrm{A}$ is also selected as the sample of the worst case.

A laboratory prototype of the bi-directional PSFB converter is built to compare the characteristics and
Table 2. System specifications and parameters of prototype

\begin{tabular}{c|c|c}
\hline \multicolumn{2}{c|}{ Parameter } & Value [Unit] \\
\hline Rated Power & $\mathrm{P}_{\max }$ & $1[\mathrm{~kW}]$ \\
\hline Rated Voltage 1 & $\mathrm{V}_{1}$ & $380\left[\mathrm{~V}_{\mathrm{dc}}\right]$ \\
\hline Maximum Current 1 & $\mathrm{I}_{1, \max }$ & $2.77[\mathrm{~A}]$ \\
\hline Rated Voltage 2 & $\mathrm{~V}_{2}$ & $350\left[\mathrm{~V}_{\mathrm{dc}}\right]$ \\
\hline Maximum Current 2 & $\mathrm{I}_{2, \max }$ & $3.00[\mathrm{~A}]$ \\
\hline Switching Frequency & $\mathrm{f}_{\mathrm{sw}}$ & $100[\mathrm{kHz}]$ \\
\hline
\end{tabular}

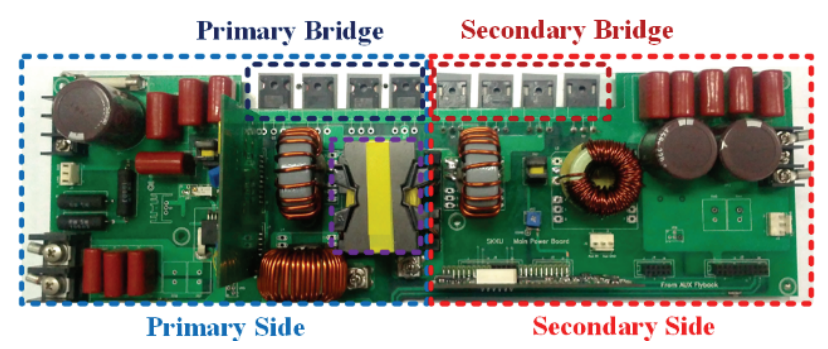

Fig. 7. Prototype of bi-directional PSFB

suitability of the sorted MOSFETs as shown in Fig. 7. The system specifications and the parameters of the prototype are listed in Table 2. By using this prototype, the experiments of each MOSFET are performed under the same conditions and the results are summarized in Fig. 8.

As shown in Fig. 8, MOSFET C can perform a relatively stable operation due to the superiority of $Q_{\mathrm{rr}}, \mathrm{t}_{\mathrm{rr}}$, and other parasitic components. MOSFET E generates the increase of the resonant current and the voltage because of the gaps of the parameters compared with MOSFET C.

When a body diode is conducted, the large transient current appears due to the growth of the reverse recovery and parasitic factors in the case of MOSFET F. From the transient, a secondary fault can be incurred by the current stress of devices. In MOSFET A, however, the failure occurs and shorts through the current flow through its main body due to the deficient reverse recovery characteristic.

According to the results of the parameter analysis and experimental comparison, MOSFET $\mathrm{C}$ is selected as the final choice for the stable operation of the bi-directional PSFB converter. In the verification, MOSFET A, which causes the failure mode in the system, is also applied on the prototype for comparison as shown in Fig. 9(a). The selected MOSFET C stably operates without the failure mode caused by the voltage spike in the primary side and the false operation of the MOSFETs in the secondary side as shown in Fig. 9(b).

Table 1. System specifications and parameter of prototype

\begin{tabular}{|c|c|c|c|c|c|c|c|c|c|c|c|c|c|c|c|c|}
\hline & \multicolumn{11}{|c|}{ MOSFET } & \multicolumn{5}{|c|}{ Body Diode } \\
\hline & $V_{D S}$ & $V_{G S}$ & $V_{G S(h)}$ & $I_{D}$ & $R_{D S(o n)}$ & $Q_{g}$ & $C_{o s s}$ & $t_{d(o n)}$ & $t_{r}$ & $t_{f}$ & $t_{d(f f)}$ & $I_{S}$ & $I_{R R M}$ & $V_{S D}$ & $t_{r r}$ & $Q_{r r}$ \\
\hline MOSFET A & $650 \mathrm{~V}$ & $20 \mathrm{~V}$ & $3 \mathrm{~V}$ & $53 \mathrm{~A}$ & $70 \mathrm{~m} \Omega$ & $170 \mathrm{nC}$ & $215 \mathrm{pF}$ & $16 \mathrm{~ns}$ & $12 \mathrm{~ns}$ & $83 \mathrm{~ns}$ & $5 \mathrm{~ns}$ & $46 \mathrm{~A}$ & $52 \mathrm{~A}$ & $0.9 \mathrm{~V}$ & $720 \mathrm{~ns}$ & $19 \mathrm{uC}$ \\
\hline MOS & $650 \mathrm{~V}$ & $30 \mathrm{~V}$ & $4 \mathrm{~V}$ & $47 \mathrm{~A}$ & $58 \mathrm{~m} \Omega$ & $210 \mathrm{nC}$ & $160 \mathrm{pF}$ & $185 \mathrm{~ns}$ & $210 \mathrm{~ns}$ & $75 \mathrm{~ns}$ & $520 \mathrm{~ns}$ & $47 \mathrm{~A}$ & - & $1.4 \mathrm{~V}$ & $590 \mathrm{~ns}$ & $25 \mathrm{uC}$ \\
\hline MOSF & $600 \mathrm{~V}$ & $20 \mathrm{~V}$ & $3 \mathrm{~V}$ & $52 \mathrm{~A}$ & $72 \mathrm{~m} \Omega$ & $165 \mathrm{nC}$ & $110 \mathrm{pF}$ & $43 \mathrm{~ns}$ & $38 \mathrm{~ns}$ & $25 \mathrm{~ns}$ & 1401 & $52 \mathrm{~A}$ & - & $1.2 \mathrm{~V}$ & $165 n s$ & $1.2 \mathrm{uC}$ \\
\hline T D & $600 \mathrm{~V}$ & $20 \mathrm{~V}$ & $2.5 \mathrm{~V}$ & $77 \mathrm{~A}$ & $41 \mathrm{~m} \Omega$ & $380 \mathrm{nC}$ & $187 \mathrm{pF}$ & 50ns & 50ns & $85 \mathrm{~ns}$ & $320 \mathrm{~ns}$ & $77 \mathrm{~A}$ & - & $1.2 \mathrm{~V}$ & 590ns & $18 \mathrm{uC}$ \\
\hline$\Gamma \mathrm{E}$ & $600 \mathrm{~V}$ & $25 \mathrm{~V}$ & $3 \mathrm{~V}$ & $51 \mathrm{~A}$ & $60 \mathrm{~m} \Omega$ & $190 \mathrm{nC}$ & $300 \mathrm{pF}$ & $33 n s$ & $68 \mathrm{~ns}$ & $96 \mathrm{~ns}$ & $188 \mathrm{~ns}$ & $51 \mathrm{~A}$ & $24 \mathrm{~A}$ & $1.3 \mathrm{~V}$ & $200 \mathrm{~ns}$ & $1.8 \mathrm{uC}$ \\
\hline MOSFET F & $650 \mathrm{~V}$ & $25 \mathrm{~V}$ & $3 \mathrm{~V}$ & $35 \mathrm{~A}$ & $88 \mathrm{~m} \Omega$ & $120 \mathrm{nC}$ & $530 \mathrm{pF}$ & $30 \mathrm{~ns}$ & $40 \mathrm{~ns}$ & $50 \mathrm{~ns}$ & $120 \mathrm{~ns}$ & $35 \mathrm{~A}$ & $22 \mathrm{~A}$ & $1.3 \mathrm{~V}$ & 190ns & $1.6 \mathrm{uC}$ \\
\hline
\end{tabular}




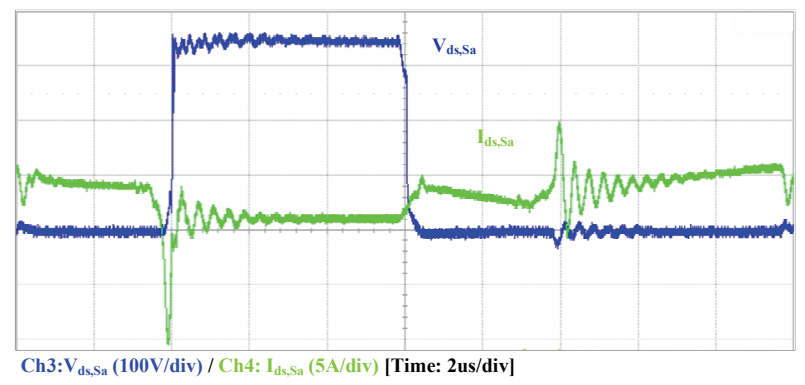

(a) MOSFET C

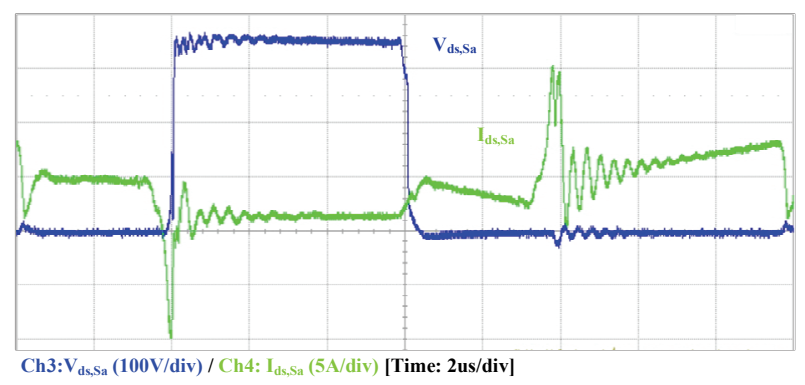

(c) MOSFET F

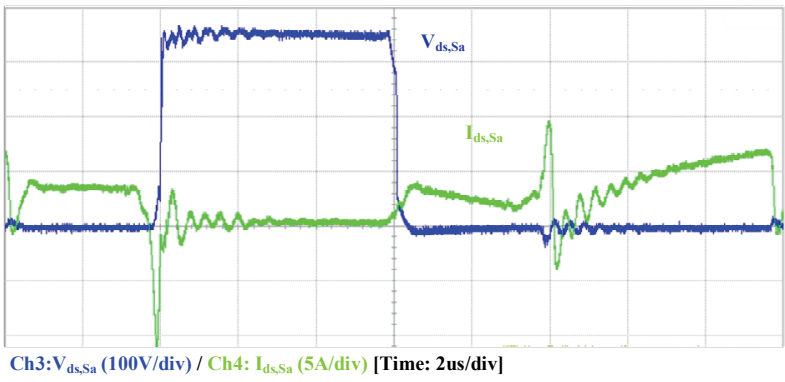

(b) MOSFET E

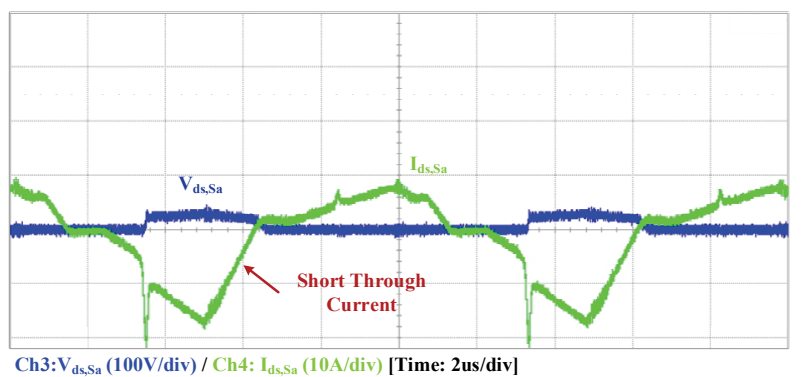

(d) MOSFET A (Failure)

Fig. 8. Experimental comparison of MOSFETs

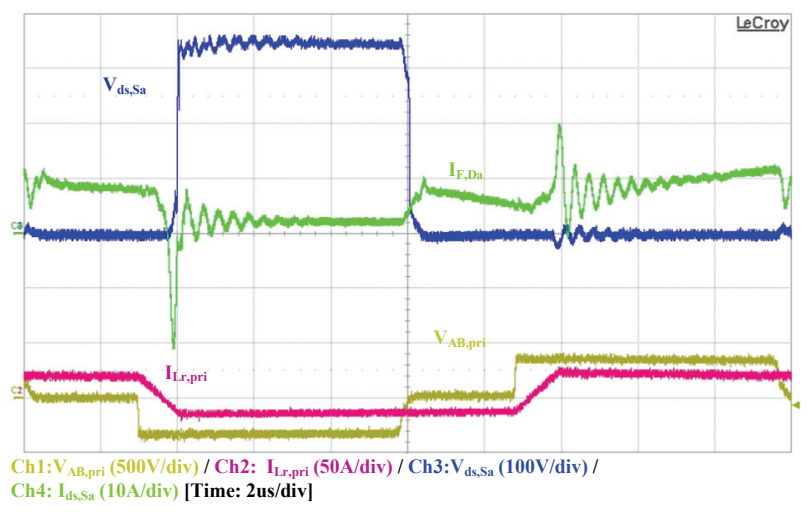

(a) Stable operation (MOSFET C)

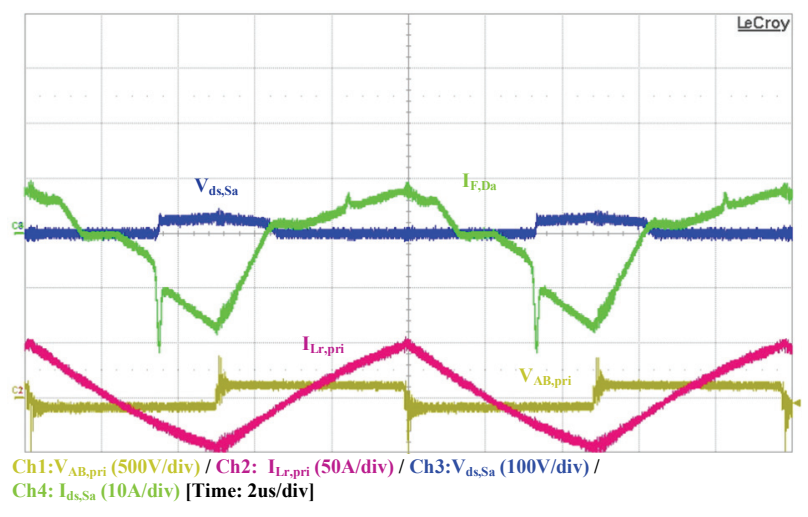

(b) Failure modes operation (MOSFET A)

Fig. 9. Verification of selected MOSFET

\section{Conclusion}

In this paper, the analysis of the mechanism of failure modes in the bi-directional PSFB converter, composed of MOSFET, was presented with a focus on the basis of the operation of the circuit and parameters with parasitic components of MOSFET. In addition, various MOSFETs have been discussed through the parameter analysis and the experimental comparison according to the transient characteristics and the parasitic components. Through the various comparisons and detailed results, the design criteria of selecting the bi-directional PSFB converter were determined. The result shows that the selected MOSFET has the following parameters: $165 \mathrm{nC}$ of $\mathrm{Q}_{\mathrm{g}}, 110 \mathrm{pF}$ of $\mathrm{C}_{\mathrm{oss}}$, $165 \mathrm{~ns}$ of $\mathrm{t}_{\mathrm{rr}}$, and $1.2 \mathrm{uC}$ of $\mathrm{Q}_{\mathrm{rr}}$. Each value of the selected
MOSFET is about $10 \% \sim 90 \%$ smaller than the parameters of other MOSFETs, and the effects of the values are shown in the result of the experimental comparison. According to the design procedure of the MOSFET in the bidirectional PSFB converter, following parameters should be considered to ensure stability and reliability:

- $\mathbf{C}_{\text {oss }}$ : The output parasitic capacitor of MOSFET $\mathrm{C}_{\text {oss }}$ influences on the ZVS condition as well as the magnitude of the voltage stress on each MOSFET in the bi-directional PSFB converter. Thus, the minimum $\mathrm{C}_{\text {oss }}$ should be one of the important factor to select the MOSFET.

- $\mathbf{Q}_{\mathrm{rr}}$ and $\mathbf{t}_{\mathrm{rr}}$ : The transient voltage caused by the reverse recovery current and the turn-on state of the parasitic BJT is controlled by the reverse-recovery 
characteristic of the body diode.

- Inductance: The ratio of magnetizing inductance to the resonant inductance $\left(\mathrm{L}_{\mathrm{m}} / \mathrm{L}_{\mathrm{r}}\right)$ maintains sufficiently large and the stray inductance $\mathrm{L}_{\sigma}$ is minimized to prevent the overvoltage failure of MOSFET with the stable operation.

- $\mathbf{V}_{\mathrm{GS}(\mathrm{th})}$ and $\mathbf{C}_{\mathrm{gd}}$ : The high $\mathrm{V}_{\mathrm{GS}(\mathrm{th})}$ and the small $\mathrm{C}_{\mathrm{gd}}$ are the main factor to avoid the failure mode by dynamic turn-on when the $\mathrm{dv} / \mathrm{dt}$ is applies across the drainsource of the MOSFET.

Through the result of the analysis, it is expected that the proposed processes can provide a design guideline for a bidirectional PSFB converter.

\section{Acknowledgment}

This work was supported by the Human Resources Development program (No.20124010203300) of the Korea Institute of Energy Technology Evaluation and Planning (KETEP) grant funded by the Korea government Ministry of Trade, Industry and Energy.

\section{References}

[1] C. Y. Oh, Y. S. Kim, W. Y. Sung, N. J. Cho, and B. K. Lee, "Analysis of MOSFET Failure Modes in Bidirectional Phase-Shift Full-Bridge Converters," in Proc. IEEE Applied Power Electronics Conf. and Expo., 2014, pp. 43-48.

[2] Md. P. Akter, S. Mekhilef, N. M. L. Tan, and H. Akagi, "Model Predictive Control of Bidirectional AC-DC Converter for Energy Storage System," Journal of Electrical Engineering \& Technology, Vol. 10, No. 1, Jan. 2015, pp. 165-175.

[3] S. J. Park, J. H. Shin, J. H. Park, and H. J. Jeon, "Dynamic Analysis and Controller Design for Standalone Operation of Photovoltaic Power Conditioners with Energy Storage," Journal of Electrical Engineering \& Technology, Vol. 9, No. 6, Nov. 2014, pp. 2004-2012.

[4] C. Zhao, S. D. Round, and J. W. Kolar, "Full-order averaging modelling of zero-voltage-switching phaseshift bidirectional DC-DC converters," IET Power Electron., vol.3, no.3, pp. 400-410, May 2010.

[5] R. L. Steigerwald, R. W. De Doncker, and H. Kheraluwala, "A comparison of high-power DC-DC soft-switched converter topologies," IEEE Trans. Ind. Appl., vol. 32, no. 5, pp. 1139-1145, Sep./Oct. 1996.

[6] D. Yu, S. Lukic, B. Jacobson, and A. Huang, "Review of high power isolated bi-directional DC-DC converters for PHEV/EV DC charging infrastructure," in Proc. IEEE Energy Convers. Congr. Expo., 2011, pp. 553-560.
[7] S. Jalbrzykowski, A. Bogdan, and T. Citko, "A Dual Full-Bridge Resonant Class-E Bidirectional DC-DC Converter," IEEE Trans. Ind. Electron., vol.58, no.9, pp. 3879-3883, Sept 2011.

[8] H. L. Chan, K. W. E. Cheng, and D. Sutanto, "ZCSZVS bi-directional phase-shifted DC-DC converter with extended load range," Proc. Inst. Elect. Eng.Elect. Power Appl., vol. 150, no. 3, pp. 269-277, May 2003

[9] G. Ma; W. Qu; G. Yu; Y. Liu; N. Liang; W. Li “A Zero-Voltage-Switching Bidirectional DC-DC Converter With State Analysis and Soft-Switching-Oriented Design Consideration", IEEE Trans. Ind. Electron., vol. 56, no. 6, pp. 2174-2184, June 2009.

[10] H. Xiao and S. Xie, "A ZVS Bidirectional DC-DC Converter With Phase-Shift Plus PWM Control Scheme," IEEE Trans. Power Electron., vol. 23, no. 2, pp. 813-823, Mar. 2008.

[11] W Li, H. Wu, H. Yu, and X. He, "Isolated WindingCoupled Bidirectional ZVS Converter With PWM Plus Phase-Shift (PPS) Control Strategy," IEEE Trans. Power Electron., vol. 26, no. 12, pp. 3560-3570, Mar. 2011.

[12] H. L. Chan, K. W. E. Cheng, and D. Sutanto, "Phaseshift controlled DC-DC convertor with bi-directional power flow," Inst. Electr. Eng. Proc.-Electr. Power Appl., vol. 148, no. 2, pp. 193-201, 2001.

[13] L. V. Karadzinov and D. C. Hamill, "Analysis of the influence of diode reverse recovery on the operation and design of high-frequency rectifiers", IEEE Trans. Power Electron., vol.15, no.2, pp.386-398, Mar. 2000

[14] S. Huang, G.A.J. Amaratunga, and F. Udrea, "Analysis of SEB and SEGR in super-junction MOSFETs", IEEE Trans. Nucl. Sci., vol. 47, no. 6, pp. 2640-2647, Dec. 2000.

[15] G. Busatto, G. V. Persiano and F. Iannuzzo, "Experimental and Numerical Investigation on MOSFET's Failure During Reverse Recovery of its Internal Diode," IEEE Trans. Power Electron., Vol. 46, No. 6, pp. 1268-1273, June 1999.

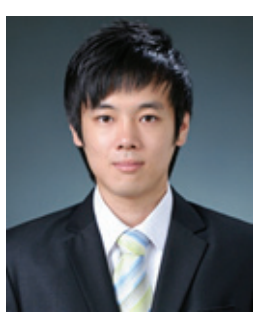

Chang-Yeol Oh He received the B.S. and the M.S. degrees from Sungkyunkwan University, Suwon, Korea, in 2011 and 2013, respectively. Since 2013, he has worked for his Ph.D in Electrical Engineering at Sungkyunkwan University. His research interests include battery charger for xEVs, high efficiency resonant converters, ESS and DC-DC converter for renewable energy. 


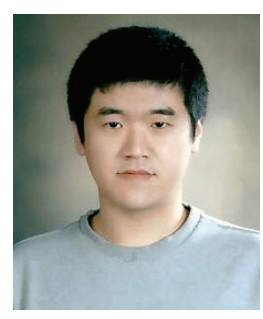

renewable energy.

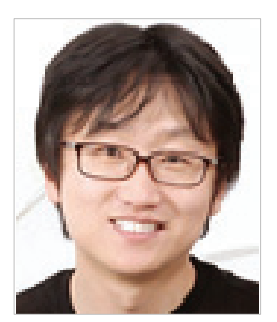

Yun-Sung Kim He received the B.S. and the M.S. degrees from Cheongju University, Cheongju, Korea, in 2000 and 2002, respectively and the $\mathrm{Ph} \mathrm{D}$. degree from Sungkyunkwan University, Suwon, Korea, in 2014. He joined the Research \& Development Center at Dongahelecomm Corporation, Yongin, Korea, in 2002 where he has worked for Advanced Development Team in R\&D Center as a Head Researcher Engineer since 2004. He is the IEEE Member. His research interests include battery charger for PHEV/EV, EESS, renewable energy conversion system, bi-directional power conversion device, and high efficiency resonant converters.

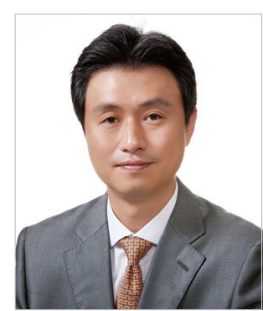

Byoung-Kuk Lee He received the B.S. and the M.S. degrees from Hanyang University, Seoul, Korea, in 1994 and 1996, respectively and the Ph.D. degree from Texas A\&M University, College Station, TX, in 2001, all in electrical engineering. From 2003 to 2005, he has been a Senior Researcher at Power Electronics Group, Korea Electrotechnology Research Institute (KERI), Changwon, Korea. From 2006 Dr. Lee joins at College of Information and Communication Engineering, Sungkyunkwan University, Suwon, Korea. His research interests include on-board charger and wireless power transfer for electric vehicles, energy storage systems, hybrid renewable energy systems, dc distribution systems for home appliances, power conditioning systems for fuel cells and photovoltaic, modeling and simulation, and power electronics. Prof. Lee is a recipient of Outstanding Scientists of the 21 st Century from IBC and listed on 2008 Ed. of Who's Who in America and 2009 Ed. of Who's Who in the World. Prof. Lee is an Associate Editor in the IEEE Transactions on Industrial Electronics and Guest Associate Editor in the IEEE Transactions on Power Electronics. He was the Presenter for Professional Education Seminar with the topic of "On-Board Charger Technology for EVs and PHEVs" at IEEE Applied Power Electronics Conference in 2014 and was the General Chair for IEEE Vehicular Power and Propulsion Conference (VPPC) in 2012. 